\title{
Introduction: Debating Drones: Politics, Media, and Aesthetics
}

\author{
Andreas Immanuel Graae, PhD Candidate, Comparative Literature, University of \\ Southern Denmark \\ Kathrin Maurer, Associate Professor, German Studies, University of Southern Denmark
}

On November 18, 2015, former President Barack Obama received an open letter from four US air force whistleblowers. With backgrounds as drone operators, the four authors all succumbed to Post Traumatic Stress Disorder (PTSD) due to their role in facilitating what they called a "systematic loss of innocent life" (Bryant et al. 2015). One of the more unsettling sentences in the letter was the following: "This administration and its predecessors have built a drone program that is one of the most devastating driving forces for terrorism and destabilization around the world" (Bryant et al. 2015). While the drone operators' critique was not exactly breaking news in 2015, it nevertheless exemplified an increasing unease and skepticism about the use of drones in 'targeted killing,' a skepticism that challenged the Obama Administration's steadfast assurances that drone strikes are just as legal as they are ethical and wise (Kaag and Kreps 2014, 1).

The global media have played an essential part in documenting the facts about drone operation in the warzones of Afghanistan, Pakistan, Yemen, and Somalia, and investigative journalists have ensured access to data, thereby countering the secrecy surrounding US drone strikes. For instance, the interactive website 'Out of Sight, Out of Mind' provides a visual map of US drone strikes, including the number of victims (both official and unofficial) from 2004 to the present. The map is updated by the Bureau of Investigative Journalism, an important and reliable player in the critical examination of drone operations. Although the legal and political framework surrounding the US drone campaign has remained rather obscure (it was never legalized by any act of Congress, nor has it ever been adjudicated by any federal court), data from inside the Administration have recently been revealed, leaked, and declassified. In October 2015, the online magazine The Intercept released a cache of leaked documents ('The Drone Papers'), which provided a glimpse into the bureaucratic processes supporting the US drone wars. These papers proved that assassination by military drones is a central tool in the US counterterrorism policy (Scahill 2015; 2016). And in November 2016, the investigative journalist and attorney Jameel Jaffer published 'The Drone Memos' providing the first fact-based insights about the legal and policy documents underlying 
US drone operations (2016). In other words, the critical media have become a central instrument in shedding light on the previous obscurity of US drone strikes. Skepticism about drones, voiced in the public debate, also reverberates in the field of popular culture. In blockbuster polit-thrillers and war films, drones are all over the place and often portrayed in rather critical light, for example in popular TV-series (e.g. Homeland and 24) as well as in high-profile Hollywood-productions like Eye in the Sky and Good Kill. And then there is of course the South Park episode on drones, where Cartman, Kenny, and Butters spy on the whole town.

The controversy about the vicissitudes of military drones carried out in public media as well as in popular culture has also swept into the academy. As the state of art in military technology, drone warfare (as well as the related systems of surveillance and the collection of big data) has sparked intense debates in political science (international relations, security studies), moral philosophy, international law, human geography, cultural studies, and media studies. Although each of these fields takes its own distinct approach towards drone warfare some conceptual concerns are shared, and are discussed across all disciplines. This special issue section of Politik aims to bring together in one volume investigations of key issues from diverging scholarly perspectives. In debating drones within the social sciences and the humanities, what are the main themes? In the respective disciplines, what arguments are used in critiques of drone warfare? Are there overlapping controversies and concerns? To find some answers to these questions, the following articles focus on an array of topics, such as the definition of warfare, asymmetrical warfare, human interaction with technology, visual architecture of the drone, as well as the representation of perpetrators and victims in aesthetic discourses. It is the goal of this issue to promote a critical consciousness about drone operations and to shape an understanding that drone warfare cannot be analyzed and explained in a mono-disciplinary fashion, but rather that its complexity demands expertise from a wide arrange of scholars.

One of our common questions is whether drone strikes can even be called wars to begin with. In his recent book, A Theory of the Drone (2015), political philosopher and anthropologist Grégoire Chamayou develops a philosophy that connects the execution of violence of the drone with practices of manhunting (Chamayou 2015). Manhunting no longer incorporates the features of the classic Clausewitzean duel; a mutual combat, a war situation, in which two opposing sides fight with each other in a declared war. Rather, a manhunt is defined by a strong hunter who advances, and a prey that hides and flees. In other words, drone operations are about targeted killings, assassinations, and the risk-free elimination of a non-declared enemy. In that sense, one can argue that drone operations are not wars.

In this context, 'asymmetrical warfare' is another key notion. In political, legal, and ethical studies, for example, the term remains crucial. The asymmetry inherent in the so-called 'riskless war' - in which drones enable the aggressor to project power without vulnerability - raises the question of whether drones are, in fact, ethical (due to their precision, and their reduction of casualties on the aggressor's side) or quite the 
contrary; that they should, again, not even be categorized within the juridical and political framework of war. This specific debate about the asymmetrical aspects of drones as constituting 'just' or 'unjust war' connects to a larger discussion about the novelty of drones as a technology of war. Thus, it is frequently debated whether drones reflect a rupture or a continuation in the political and technology history of warfare. Within international law studies, drone warfare can be seen as a new type of war that not only undermines international law but also require new forms of legislation (Kahn 2013; Moyn 2013).

Anders Henriksen and Jens Ringsmose, in their article 'The Moral of the Battlefield and the Risk-Free War with Drones,' address precisely this intersection between security studies, moral philosophy (ethics), and law. Essentially, risk-free drone operations embody a form of asymmetrical warfare that represents what Michael Walzer (2000) classifies as a form of unjust war. Henriksen and Ringsmose show that the widespread skepticism of drone warfare is due to the fact that war is still conceived as a moral and political endeavor, as Carl von Clausewitz's proposed in his treatise $O n$ War published in 1832. Their argument is that many people - consciously or unconsciously - feel that war ought to be a reciprocal affair (involving danger and risk on both sides). Yet, drone warfare, the authors propose, eliminate this balance since the lack of reciprocity constitutes an inherent paradox: On the one hand, casualties should be minimized, but, on the other hand, the targeted reduction of casualties (or: assassinations) is precisely what many people find as morally problematic.

The debate about drone warfare and ethics reflects a wide spectrum of diverse opinions and views. While some scholars consider the absence of morality in drone operations to disqualify these from even being regarded as a form of warfare (Chamayou 2015; Maurer 2016), some military ethicists argue that drone warfare is (and even must be) a moral affair. Bradley Jay Strawser, for example, claims that, because drones do save lives of the just, they are not only ethical in themselves but, in fact, they impose on political decision makers a moral duty to use them: "I contend that in certain contexts UAV (unmanned aerial vehicle) employment is not only ethically permissible, but is, in fact, ethically obligatory" (Strawser 2010, 344). Because drone operators fight just wars, according to Strawser's logic, their means of fighting in these wars are also just, and therefore the jus in bello law and the jus ad bellum law are not impeded. If one is fighting a just war, it is only good that the means are asymmetrical, and that the just warrior is better protected than the unjust one. The public version of this argument is illustrated in a US Air Force commercial image appearing in the magazine Popular Science (Sweetmann 1997, 95-101). The photo shows a gleaming remote controlled combat plane against a brisk blue sky with the heading 'Nobody dies but the enemy' conveying the idea of a clean, sanitized and just war.

The argument for minimizing the killing of civilians is powerful indeed, and, when faced with a plethora of normative moral claims that serve utilitarian ends, it can be difficult for scholars and critics to maintain a focus on laying bare the assumptions that underlie such claims. Ezio Di Nucci's article, 'Drones and the Threshold for 
Waging War,' engages with ethical claims about drone warfare by discussing the works of military ethicists, such as Zack Beauchamp, Julian Savulescu, and Strawser. Whereas Chamayou has termed their ethics as an ideology of 'killing well,' a so-called 'necroethics' (Chamayou, 2015), and thus denies even their status as ethicists, Di Nucci analyzes their argumentative logic and their analytical methods. In doing so, Di Nucci essentially follows the dictum of Beauchamp and Savulescu that drones can reduce casualties and can thus dangerously lower the threshold for waging conventional forms of war. He challenges them, however, by his claim that the fact that drones make the waging of wars easier is not a bad thing, because lowering the threshold to war could entail some positive consequences such as improving the 'just' practices of humanitarian intervention.

This type of analytical and pragmatic reasoning about drone warfare is not only contested by other scholars of philosophy (Chamayou 2015, Gros 2010), but also by a field of scholarship that has become more and more visible with respect to remote control warfare during the last decades: the human geographers. Peter Adey, Iain Shaw and Derek Gregory have published extensively on the geopolitical, topological, and emotional contexts of drone wars, the latter through his highly informative and widely cited blog 'Geographical Imaginations' (Adey 2010; Adey et al. 2013; Shaw 2016; Gregory 2004, 2011, 2014). Gregory analyzes the ways that experiences of time and space have fundamentally changed with the rise of military drones, a change that he described with the term 'imaginative geographies.' Gregory analyzes, for example, the wide-area surveillance technology with the telling name of Gorgon Stare, which is able to capture motion imagery of a whole city (Gregory 2011). Gorgon Stare incorporates a spherical array of nine cameras attached to an aerial drone armed with Hell Fire Missiles. Together with Gorgon's brother, the surveillance technology Argus-IS (again a pun on mythology), containing hundreds of cell phone-like high-resolution cameras, can quilt together a mega-stream of images into a large-scale mosaic and feed them into the data networks of stations on the ground.

Gorgon and Argus certainly transform the human experience of space and time; as a drone pilot notes: "Sometimes I felt like a God hurling thunderbolts from afar" (Gregory 2011, 192). Given these Olympian powers, drawing a parallel to Jeremy Bentham's panopticon seems imperative. Like that of the panopticon, the perspective afforded by such wide-area technologies suggests a totalized and synoptic view of the surveyed object. The philosopher Zygmunt Bauman, however, has pointed out that the visual field of surveillance of the drone is in fact far more powerful than that of the panopticon, since it requires neither spatial partitions nor fixed architectural demarcations. The effects of this multi-scopic gaze become quite clear when one looks at the spherical distribution of cameras like Gorgon Stare and Argus-IS that are no longer organized via a centralized verticality (i.e. the watch tower of the panopticon), but rather along a multi-faceted gaze whose constellations can constantly change. Drones embody what Bauman calls a 'liquid technology' - one that is no longer perpendicularly ordered, but is decentralized, flexible, and fluid $(2013,67)$. 
It is striking that military drones do not only invert spatial and temporal forms of experience, but also have a decisive impact on the emotional experience of the individual soldier (or drone operator). Drones create geographical and temporal distance, but at the same time they bring the battlefield intimately close by live-feed video signals. This closeness affects the individual perception of drone operators, who often watch their targets for weeks or months before eventually eliminating them. Remember the public letter to the president, signed by four drone pilots. The motivation behind the letter was indeed a growing unease and guilt triggered by posttraumatic stress, which is shared by many other drone operators.

Whereas human geographers document the sensor operator's psychological reactions to this new kind of 'voyeuristic intimacy' in remote warfare (Gregory 2014), cultural studies and media studies frequently focus on the technologies with which these emotions are entwined. How do humans interact with these new technologies of seeing? What does a drone operator see (versus what is seen by his or her optical sensor machine)? What is the relationship between these new modes of physical and technological perception? Are they interlinked? Who or what is in charge when executing these missions? To approach these questions, the theoretical distinction between vision and visuality is helpful. Vision refers to the physical condition of seeing, the human eye, and visuality describes seeing as a social construction and its technologies (Foster 1998). According to Hal Foster, these terms become deeply intertwined within the course of modern scientific rationalization. In the case of latemodern drone warfare, the boundaries between vision and visuality become completely blurred. Nina Franz and Rebekka Ladewig's article, 'Synthetic Reality and Blind Flight: The Operationalization of Perception,' investigates the conditions of drone vision and visuality from a media historical, media theoretical, and political perspective. A key term is 'situational awareness', which expresses a condition in which technology and the human senses are merged, and in which images gain a form of operative power. Situational awareness is a crucial aspect of decision making within military operations and foreign policy, which is, according to the authors, deeply problematic. According to them, situational awareness is based on the logic of simulation of a post-democratic form of government as suggested in Jacques Rancière's work Disagreement: Politics and Philosophy (1999).

The construction and impact of 'operative images' in drone warfare are also vital to Moritz Queisner's media theoretical analysis in this themed section of Politik. Queisner's article, 'Looking Through a Soda Straw: Mediated Vision in Remote Warfare', investigates the effects of the remote gaze of drone operators on their decision-making processes. He argues that the visual architecture of drones - or their scopic regimes (Gregory 2014; Maurer 2016) - redefines the relationship between human actors and machines. Neither the human subject nor the machine is completely in control of the decision-making processes during drone operations. Rather, as Queisner proposes, the scopic regime of the military drone suggests an in-between space with which the human is entangled in a socio-technological assemblage. Within 
this constellation, humans and technology merge; a union that, in the context of drone attacks, can be critical when it comes to life and death decisions.

Discussing drones in an interdisciplinary fashion must also reach beyond questions of political, strategic, ethical, technological, and medial frames. To understand drone warfare and its ramifications for the individual (in particular, for the sensor operators and the victims) it is imperative to investigate its representation in the aesthetic realm (photography, film, literature, art). Aesthetics and its non-instrumental potential represent a discourse that is well suited to voice a critical perspective. As noted above, there is a current boom in films about drone operations. But it is not only Hollywood that has discovered the drone. Works by independent visual artists, such as Omer Fast's film 5000 Feet is the Best (2011), also shed light on the impact of drone warfare on the human individual. Photographers, musicians, and literary writers have likewise dealt with the drone as an aesthetic object. In fact, considering the amount of drone-related art, and the increasing aesthetic interest in this technology, one could declare the existence of an aesthetic 'drone imaginary'. A central part of this aesthetic drone imaginary is the concern with the secrecy and invisibility of drone operations which could be why drones are, as essayist Adam Rothstein writes, "shrouded in fantasy" (Rothstein 2015, ix).

Andreas Immanuel Graae investigates a specific aesthetic drone imaginary, namely the one represented in the television series Homeland, in which the bipolar CIA agent Carrie Mathison conducts several drone strikes. Graae's article in this volume, 'The Drone Queen: Voyeurism, Intimacy, and Paranoia in the TV-Series Homeland', explores the voyeuristic intimacy that comes with the scopic regime of the drone. Graae points to the split experience undergone by drone operators as they conduct attacks, during which they are simultaneously emotionally present and geographically removed. This split, or shattered experience, is embodied in Carrie Mathison's paranoia, bipolarity and simultaneous ability to manically decode messages in mosaic-like big data flows. Graae's article suggests that, in the aesthetic representation of drone warfare, such as in Homeland, this split experience can be affectively communicated to the viewer and, furthermore, can also mark a paranoid connection between drone warfare and the war against terror in general.

With these diverse contributions, this theme issue hopes to show that there are nevertheless common threads between the individual disciplines in the drone debate. Notions of asymmetrical warfare, risk-free attacks, visibility and invisibility, as well as an interest in the emotions surrounding drone technology are (to different degrees, of course) pertinent to all articles. It is important for us to convey that drone operations are not an affair about which only policy makers, military experts, and technologists have a say. Drone warfare represents a societal phenomenon whose complexity can only be grasped by a multi-disciplinary view, involving scholars from the social sciences as well as the humanities. 
The timeliness and relevance of this issue are sinisterly acute. A new era of American foreign policy has just been inaugurated with a President Trump who declares an intensified war on terror with the smallest possible cost to America. On national television, Trump has openly vowed to 'take out' the civilian families of Islamic State fighters as part of his anti-terror strategy. Despite their use by Trump's predecessor, this posture could most certainly imply an unprecedented intensification of the use of drones for targeted killings. During the last part of his presidency Obama did, in fact, create a policy under which drone strikes should only be undertaken against a terrorist target outside a war zone if there was a 'near certainty' that no civilian would be harmed. But since Trump will wage a less 'politically correct' war, as he says, Obama's drone policy could be instantly superseded. According to Stephen Vladeck, a national security expert at the University of Texas School of Law, the consequences would be hard to detect from the outside, since the strikes in question are classified: "If more civilians were killed in covert CIA drone strikes, the US would likely not acknowledge that, and journalists may or may not even learn about it. But such increased aggression would mean much more conflict with our foreign partners" (Dilanian 2016). The new president's relation to the truth does certainly not make the picture any brighter. In fact, Trump could reshape the US drone policy with an even higher degree of secrecy and falsehood. In presenting this issue, we urgently hope to counter this secrecy and instead foster a discursive climate in which the views of scholars across all disciplines are taken more widely into account as serious contributions to a discussion in which human lives are daily and increasingly at stake.

\section{References}

Adey, P 2010, Aerial Life: Spaces, Mobilities, Affects, Malden, MA, Wiley-Blackwell.

Adey, P; M Whitehead \& A Williams 2013, From Above: War, Violence, and Verticality, New York, NY, Oxford University Press.

Bauman, Z \& D Lyon 2013, Liquid Surveillance: A Conversation, Cambridge, Polity Press.

Bryant, B; C Westmoreland, S Lewis \& M Haas 2015, 'Letter for President Barack Obama'. 18 November 2015. Available at:

https://www.documentcloud.org/documents/2515596-final-drone-letter.html [Accessed 18 January 2017].

Chamayou, G 2015, A Theory of the Drone, New York, The New Press.

Dilanian, K 2016, 'How Trump Can Gut Obama's National Security Policies on Day One'. NBC News, 14 November 2016.

Foster H 1998, Vision and Visuality, Seattle, Bay Press. 
Gregory, D 2004, The Colonial Present: Afghanistan, Palestine, and Iraq, Malden, MA, Blackwell Pub.

Gregory, D 2011, 'From a View to a Kill', Theory, Culture \& Society, vol. 28, pp. 188215.

Gregory, D 2014, 'Drone Geographies', Radical Philosophy, vol. 183, pp. 7-19.

Gros F 2010, States of Violence, Trans. K Fijalkowski \& M Richardson, London, Seagull Books.

Jaffer, J 2016, The Drone Memos: Targeted Killing, Secrecy, and the Law, New York, The New Press.

Kahn, P W 2013, 'Imagining Warfare', European Journal of International Law, vol. 24, pp. 199-226.

Kaag, J \& S E Kreps 2014, Drone Warfare, Cambridge, UK, Polity.

Maurer, K 2016, 'Visual Power: The Scopic Regime of Military Drone Operations', Media, War \& Conflict. Available at: http://journals.sagepub.com/doi/full/10.1177/1750635216636137, 1-11.

[Accessed 18 January 2017]

Moyn, S 2013, 'Drones and Imagination: A Response to Paul Kahn', European Journal of International Law, vol. 24, pp. 227-233.

Rothstein, A 2015, Drone, New York, Bloomsbury Academic, an imprint of Bloomsbury Publishing Inc.

Scahill, J et. al. 2015, 'The Drone Papers', The Intercept. Available at: https://theintercept.com/drone-papers/ [Accessed 18 January 2017].

Scahill, J 2016, The Assassination Complex: Inside the Government's Secret Drone Warfare Program, New York, Simon \& Schuster.

Shaw, I G R 2016, Predator Empire, Drone Warfare and Full Spectrum Dominance, Minneapolis, University of Minnesota Press.

Strawser B 2010, 'Moral Predators: The duty to Employ Uninhabited Aerial Vehicles', Journal of Military Ethics, vol. 9, no. 4, pp. 342-368.

Sweetman B 1997, 'Fighters without Pilots', Popular Science, vol. 11, pp. 97-101.

Walzer M 2000, Just and Unjust Wars: A Moral Argument with Historical Illustrations, New York, Basic Books. 